\title{
A flexible closed-loop (fcl) pid and dynamic fuzzy logic + pid controllers for optimization of dc motor
}

DOI : 10.36909/jer.13813

\author{
"Erol Can and **"Mustafa Serdar Toksoy \\ "Department of Aviation Electric Electronics, School of Civil Aviation, Erzincan Binali Y1ldırım \\ University \\ ** Quality Coordination Office, Erzincan Binali Yıldırım University \\ Correspondence: cn_e@ @hotmail.com
}

\begin{abstract}
:
For electrical machines and power circuits to operate at high performance, it is important to control them at the optimum point. So, in this study, a flexible closed-loop (FCL) PID and PID FUZZY study is presented. Different from other studies, different controls can be activated for different positions and durations within the total operating time of the motor. At the same time, by applying four inputs for fuzzification in the designed fuzzy logic control section, 3 different outputs are provided to the PID control in three defuzzification sections. So, Dynamic Fuzzy logic interactivity is ensured with PID on load. This, unlike other PID FUZZY controllers, provides a more effective application of error and error change to the system. In the second chapter, DC motors and controls are explained. In the third chapter, designed controls and dc motor applications are made. The results obtained in practice reveal the effectiveness of the proposed system after compared with conventional P, PI and PID.
\end{abstract}

Key words: a flexible closed-loop, PID FUZZY, optimum point, Dynamic Fuzzy logic

\section{INTRODUCTION}

DC motor is a high-efficiency, durable machine that converts electrical energy into mechanical energy and produces high torque according to its volume (Tang, et al.,2017). They have relatively simple controllable speed ranges compared to other motors (Jaya, wt al., 2018) because of their advantages, they have applications in many fields in Industry farming and social life. DC motors have been studied for different robot applications. While investigating the DC motor application used to provide navigation in the versatile movement of mobile robot applications (Yunardi, et al.,2021), a Proportional Integral Derivative (PID) controlled DC motor system is recommended to regulate the speed at the mini conveyor (Latif, et al.,2021). Motor control applications for a pump find effective application areas in irrigation and agriculture (Mondal, et al., 2020 ,Workineh, et al., 2021; Assefa, et al.,2021; Mseddi, et al.2021). DC voltage regulated by PID or FUZZY Logic Controller controlling a dc-dc converter or a dc voltage source switch at the input in DC motor applications can control speed, voltage, and position (Can et al., 2017; Mahmud, et al., 2020; Arulmozhiyal, and Kandiban, 2012). Also, an alternating voltage rectified by the PID controlling switches can provide energy to dc voltage applications (Rezaie, et al., 2020). In these given applications, the control methods applied to the motor start with the control mechanism at the beginning of the total control period, and the same control mechanism at the end of the control period affects the system. They are insufficient to include different control systems in the system at different times to the total engine run times. Therefore, Flexible Closed-Loop (FCL) P + PID, PI + PID and PID + Fuzz control methods are recommended. With the proposed method, when control starting with PI is necessary, the system can switch to PID instantly while it is still operating. At the same time, control starting with PID can continue with Fuzzy. Unlike other DC motor control methods, different control methods are activated within the same control period and an effective control mechanism that differs according to the situation is offered. In previously studied Fuzzy PID applications while more than one input is applied in fuzzy set, a single output is sent to three control units in Defuzzification (Saeteros,et.al.,2019) In the proposed method, 3 different outputs in three defuzzification section are sent to three different control units, providing an effective change in error and error change rates. Also, as different controllers can be activated in different parts of the total control time, dynamic control is provided by sending three outputs from three different defuzzification to the PID control at a time. Considering the results obtained, FUZZY PID control with dynamic interaction stabilizes dc motor values more quickly with less oscillation compared to traditional methods. 


\section{MOTOR AND FUZZY + PID}

The motor torque is linearly changing on the armature current according to as Eq1.

$\operatorname{Tm}(s) / I a(s)=K m$

$(s)$ : the motor torque in S-domain. : The DC machine torque constant. Using the Kirchhoff's law, the summation of the voltage in a circuit equal to zero, then the following equation calculated

$E a=E_{L}+E_{b}=i_{a} R_{a}+L_{a} d i_{a} d t+K_{b} \theta_{m}$

$R a$ : the resistance of the motor. $L a$ : the inductance of DC machine. $K b$ : the velocity constant. $\theta m$ : the angular velocity of DC machine.

For the free body connected to the motor rotational motion is formulated by

$J \omega+c \omega=T m$

$\omega$ : the angular velocity of DC machine, c: motor friction constant of DC machine, J: the moment of the rotor inertia at DC machine. If Laplace transform of Equation (1) is transformed, the following equation as below:

$\omega(s) / \mathrm{T}(s)=1 /(\mathrm{J} \mathrm{s}+C)$

$G(s)=\omega(s) / E a(s)=K m /\left[\left(L_{a} s+R a\right)(J s+c)+K_{b} K_{m}\right]=K m \quad / \quad\left[L_{a} J s^{2}+\left(R a J+L_{a} c\right) s+\left(R_{a} c+K_{b} K_{m}\right)\right]$

The PID controller is a feedback control loop mechanism commonly used in device control system response. The controller tries to minimize the error by adjusting the process control input according to the feedback it receives. In the PID controller calculation algorithm, there are three constant parameters known as proportional (P), integral (I), and derivative (D) values, these values can be interpreted in terms of time. $\mathrm{P}$ is based on current error, I is an accumulation of past error and D is a possible prediction of future error based on current rates of change. The weighted sum of these three actions is used to adjust the operation rate of a control switch or the action through a control element such as the power supplied to a device.

$U(t)=e(t) K_{P}+K_{I} \int_{0}^{t} e(t)+\frac{K_{D} d e(t)}{d t}$

$K P$ : proportional gain using to increase the system response speed and reduce steady-state error. $K I$ : integral gain using to eliminate the steady-stat error at all. $K D$ : derivative gain used to reduce the system response overshoot. The transfer function is expressed as follows,

$C(s)=K_{P}+K_{i} / s+K_{d} s$

In the proposed control method, the total working time of the system is divided by steps and two different control systems can be applied to the total working time. This provides us with a flexible changeable closed loop control method. While different energy sources are put into use to drive the system with both the step method, a different control system can be applied in another part of the total working time. If the total run time is divided by two equal part steps such as PID for the first step and PI for the second step, the control equation for the total run time will be as follow

$U(t)=e(0.5 t) K_{P}+K_{I} \int_{0}^{0.5 t} e(t)+\frac{K_{D} d e(t)}{d t}+e(0.5 t) K_{P}+K_{I} \int_{0.5 t}^{t-0.5 t} e(t)$

The control equation for KI can be arranged as follows in $\mathrm{y}(\mathrm{t})$.

$$
\begin{aligned}
& y(t)=K_{I} \int_{0}^{0.5 t} e(t)+\frac{K_{D} d e(t)}{d t}+K_{I} \int_{t-0.5 t}^{t} e(t) \\
& y(t)=y(t-0.5 t)+\Delta_{y}(t-0.5 t) \\
& \Delta_{y}(t-0.5 t)=K l \cdot t e(t-0.5 t)+\frac{K l}{2} \cdot t[(e(0.5 t)+e(0.5 t-t)]
\end{aligned}
$$


$\Delta_{y}=\frac{K l}{2} \cdot t[(e(0.5 t)+e(0.5 t-t)]$

If Eq. 13 is added in Eq.11, then Eq. 14 is formed as below;

$y(t)=y(t-0.5 t)+\frac{K l}{2} \cdot t[(e(0.5 t)+e(0.5 t-t)$

If $\mathrm{z}$ transform is applied in Eq 14, then Equations are obtained as below;

$y(z)=y(z) 0.5 z^{-1}+\frac{K l}{2} \cdot t\left[\left(e(z)+e(z) 0.5 z^{-1}\right]\right.$

$\frac{y(z)}{e(z)}=\frac{K \iota}{2} \cdot t\left[\frac{1+0.5 z^{-1}}{1-0.5 z^{-1}}\right]=\frac{K \iota}{2} \cdot t\left[\frac{0.5 z+1}{0.5 z-1}\right]$

If equation 9 is arranged as a $\mathrm{z}$ transfer function, equation 17 is obtained.

$U(z)=K_{P}+\frac{K l}{2} \cdot t\left[\frac{0.5 z+1}{0.5 z-1}\right]+K_{D} \frac{1}{t}\left[\frac{z-1}{z}\right]$

PID closed-loop control of the DC motor is as shown in figure 1. Here, the total working time is divided into two equal periods. In the first step, the dc motor starts to operate at a lower speed, while in the second step a higher voltage is applied to the motor and more speed is provided to the motor. PID controller is active in both time zones. PID and PI closed-loop control of the DC motor is as shown in figure 2. Here, the total working time is divided into two equal periods. In the first step, while the dc motor starts to run at a lower speed, the PID controller controls the motor. In the second step, a higher voltage is applied to the motor with the PI control to provide more speed. Thus, flexible closed-loop control is provided by using different controls in both time periods of the total run time.

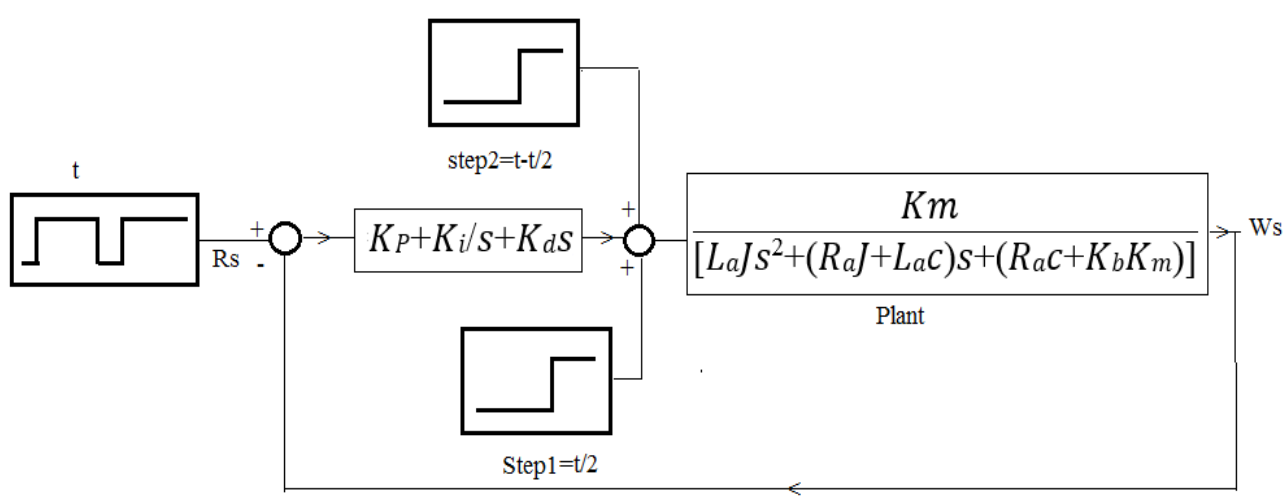

Figure1. PID closed-loop control of the DC motor at two time zones 


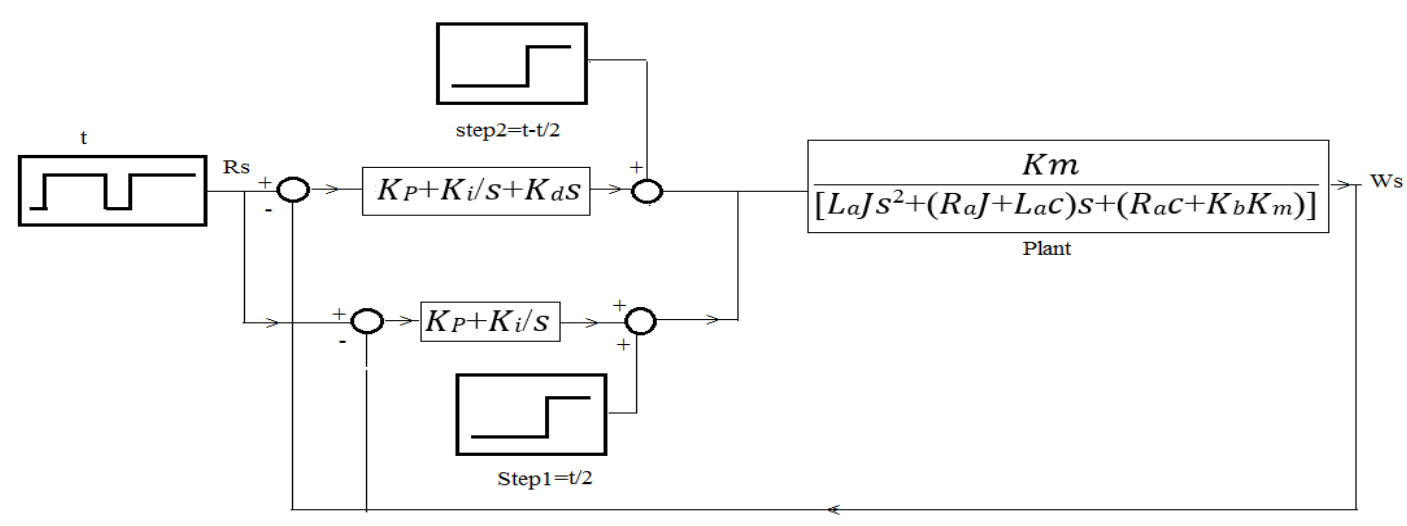

Figure2. PID and PI closed-loop control of the DC motor at two time zones

Some researchers are developing PID control strategies based on some intelligent algorithms using a fuzzy logic algorithm. (Kristiyono,et al.,2021; Premkumar, et al.,2021; Do Khac Tiep, et al,2018). While the PID is adjusted by sending a single output obtained in three defuzzification section to the three inputs of the PID control, in the proposed method, the PID is adjusted by obtaining three different outputs in defuzzification. Therefore, dynamic control is provided by sending 3 outputs from three different defuzzification to the PID control at a time. In these studies, the self-adjusting fuzzy PID controller uses the Fuzzy Inference System to adjust $\mathrm{Kp}, \mathrm{Ki}$, and $\mathrm{Kd}$ parameters according to error (e) and error derivative (e). In the proposed system, different $\mathrm{Kp}, \mathrm{Kd}$, and $\mathrm{K}$ values obtained by an error change of three different errors are transmitted to the PID Control. The error (e) depends on the reference signal $r(k)$ and the output signal $y(k)$, expressed as in eq.18 while error (e) and change of error (de) are as in eq. 19.

$$
\begin{aligned}
& e(k)=r(k)-y(k) \\
& d e(k)=e(k)-e(k-1)
\end{aligned}
$$

In the proposed system, the interaction of three different errors through one error change is used. Fuzzy logic sets have triangle membership functions. The interaction of these membership functions is given in Figure 3.Ep is the error of $\mathrm{P}$, Ei is the error of in, and Ed is the error of D. In the same order, DEp, DEi and DEd express the variation of errors. They can be expressed in the following equations.

$$
\begin{aligned}
& \operatorname{Ep}(k)=r\left(k_{1}\right)-y\left(k_{1}\right) \\
& \operatorname{DEp}(k)=\operatorname{Ep}\left(k_{1}\right)-\operatorname{Ep}\left(k_{1}-1\right) \\
& \operatorname{Ei}(k)=r\left(k_{11}\right)-y\left(k_{11}\right) \\
& \operatorname{DEi}(k)=E p\left(k_{11}\right)-E p\left(k_{11}-1\right) \\
& \operatorname{Ed}(k)=r\left(k_{12}\right)-y\left(k_{12}\right) \\
& \operatorname{DEp}(k)=\operatorname{Ep}\left(k_{12}\right)-\operatorname{Ep}\left(k_{12}-1\right)
\end{aligned}
$$




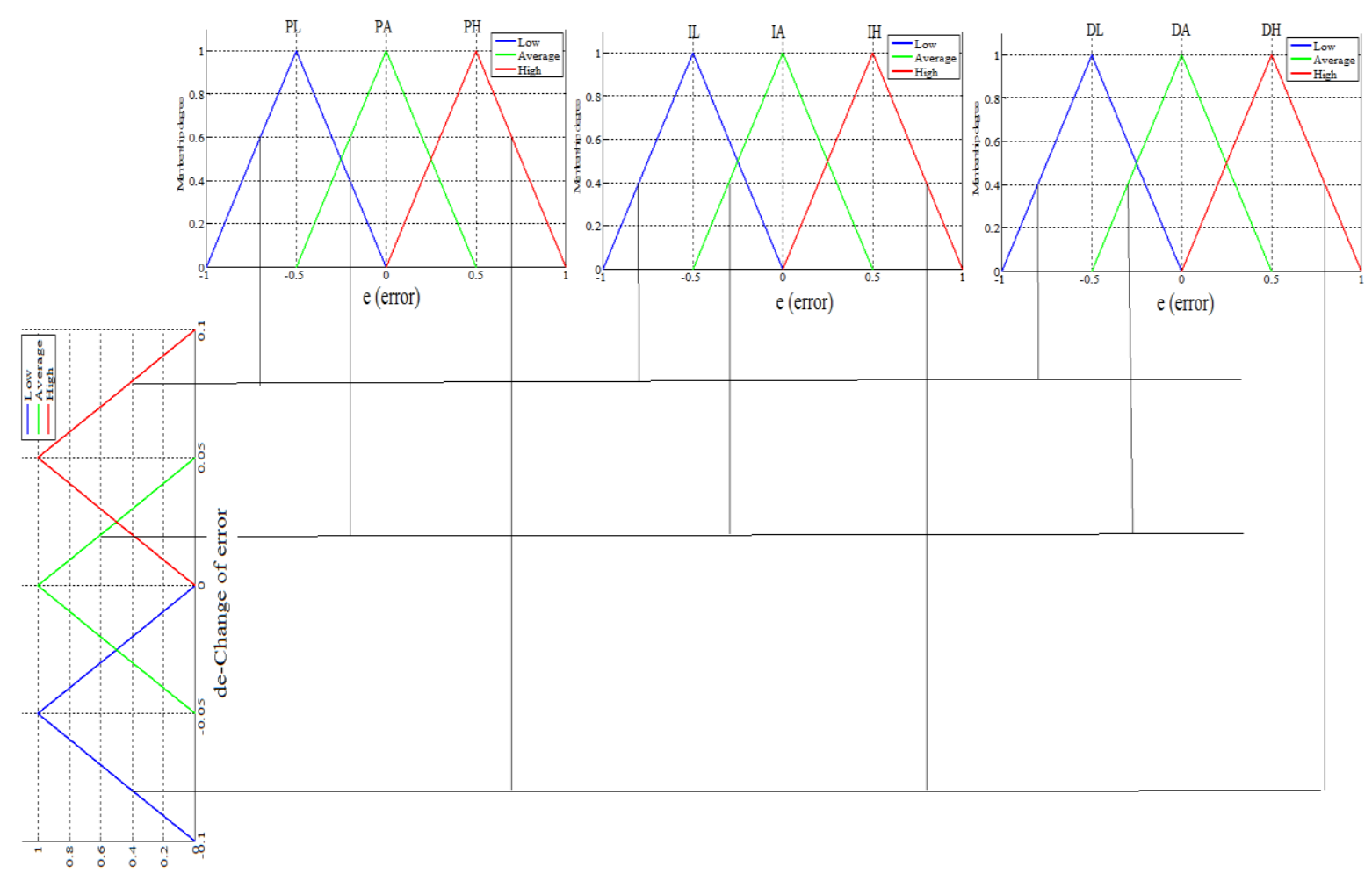

Figure 3. The interaction of these membership functions.

Each fuzzy settlement consists of three membership functions. PL is low of P; IL is the low of I; DL is the low of D. PA is the average of P; Mean of IL I; DL is the average of D. Higher of P; Higher of IL I; DL is higher of $\mathrm{D}$. The 3-member fuzzy logic rule table is given as in table 1. The 5-member fuzzy logic rule table is given as in table 2.

Table 1.The 3-member fuzzy logic rule

\begin{tabular}{|l|l|l|l|l|l|l|l|l|l|l|}
\hline \multirow{3}{*}{$\begin{array}{l}\text { DEp } \\
\text { DEi }\end{array}$} & \multicolumn{3}{|c|}{ Ep } & \multicolumn{3}{c|}{ Ei } & \multicolumn{3}{c|}{ Ed } \\
\cline { 2 - 10 } & PEp & PA & PA & PH & IA & IA & IH & DL & DA & DH \\
\cline { 2 - 10 } & A & PH & PA & PH & IA & IA & IH & DA & DA & DH \\
\cline { 2 - 10 } & L & PL & PH & PA & IL & IA & IA & DH & DA & DA \\
\cline { 2 - 10 } & \multicolumn{3}{|c|}{ Dup } & \multicolumn{3}{|c|}{ Dui } & IA & DA & DH & DA \\
\hline
\end{tabular}

Table 2.The 5-member fuzzy logic rule

\begin{tabular}{|c|c|c|c|c|c|c|c|c|c|c|c|c|c|c|c|c|}
\hline \multirow{7}{*}{$\begin{array}{l}\text { DEp } \\
\text { DEi } \\
\text { DEp }\end{array}$} & & \multicolumn{5}{|c|}{$\mathrm{Ep}$} & \multicolumn{5}{|c|}{$\mathrm{Ei}$} & \multicolumn{5}{|c|}{$\mathrm{Ed}$} \\
\hline & & PLs & PLb & PA & PHs & PHs & ILs & ILb & IA & IHs & $\mathrm{IHb}$ & DLs & DLb & DA & DHs & $\mathrm{DHb}$ \\
\hline & Ls & PLs & PLs & PLs & PLs & PLs & ILs & ILs & ILs & ILs & ILs & DLs & DLs & DLs & DLs & DLs \\
\hline & $\mathrm{Lb}$ & PLb & PLs & PLb & PLb & PLs & ILb & ILs & ILb & ILb & ILs & DLb & DLs & DLb & DLb & DLs \\
\hline & A & PLb & PLs & PA & PL & PHs & ILb & ILs & IA & IL & IHs & DLb & DLs & DA & DL & DHs \\
\hline & Hs & PLs & PLs & PHs & $\mathrm{PHb}$ & $\mathrm{PHb}$ & ILs & ILs & IHs & $\mathrm{IHb}$ & $\mathrm{IHb}$ & DLs & DLs & DHs & $\mathrm{DHb}$ & $\mathrm{DHb}$ \\
\hline & $\mathrm{Hb}$ & $\mathrm{PHb}$ & $\mathrm{PHb}$ & $\mathrm{PHb}$ & $\mathrm{PHb}$ & $\mathrm{PHb}$ & $\mathrm{IHb}$ & $\mathrm{IHb}$ & $\mathrm{IHb}$ & $\mathrm{IHb}$ & $\mathrm{IHb}$ & $\mathrm{DHb}$ & $\mathrm{DHb}$ & $\mathrm{DHb}$ & $\mathrm{DHb}$ & $\mathrm{DHb}$ \\
\hline & & \multicolumn{5}{|c|}{ Dup } & \multicolumn{5}{|c|}{ Dui } & \multicolumn{5}{|c|}{ Dud } \\
\hline
\end{tabular}

Dup, Dui, and Dud represent the outputs that will occur as a result of the intersection of membership functions. The network to be established is as given in figure 5. The relationship between error and error changes is equally as follows. ei (n) : output error integral ep (n) : output error proportional ed (n) : output error differential vi (n) 
$: i^{\text {th }}$ inferential value. $\mu$ is the degree of membership. Defuzzification for the three outputs can be expressed as follows ;

$$
\begin{aligned}
G\left(e_{p}\right)=\sum_{i=1}^{9} \mu_{i} k_{1} & =k_{1}\left(\mu_{L}\left(e_{p}\right) \mu_{L}\left(e_{p}\right) \mu_{L}\left(e_{p}\right)\right)+k_{2}\left(\mu_{L}\left(e_{p}\right) \mu_{L}\left(e_{p}\right) \mu_{A}\left(e_{p}\right)\right) \\
& +k_{3}\left(\mu_{L}\left(e_{p}\right) \mu_{A}\left(e_{p}\right) \mu_{H}\left(e_{p}\right)\right)+k_{4}\left(\mu_{L}\left(e_{p}\right) \mu_{H}\left(e_{p}\right) \mu_{A}\left(e_{p}\right)\right)+k_{5}\left(\mu_{A}\left(e_{p}\right) \mu_{L}\left(e_{p}\right) \mu_{A}\left(e_{p}\right)\right) \\
& +k_{6}\left(\mu_{H}\left(e_{p}\right) \mu_{A}\left(e_{p}\right) \mu_{L}\left(e_{p}\right)\right)+k_{7}\left(\mu_{A}\left(e_{p}\right) \mu_{L}\left(e_{p}\right) \mu_{L}\left(e_{p}\right)\right)+k_{8}\left(\mu_{L}\left(e_{p}\right) \mu_{A}\left(e_{p}\right) \mu_{A}\left(e_{p}\right)\right) \\
& +k_{9}\left(\mu_{A}\left(e_{p}\right) \mu_{A}\left(e_{p}\right) \mu_{A}\left(e_{p}\right)\right)
\end{aligned}
$$

$$
\begin{aligned}
G\left(e_{i}\right)=\sum_{i=1}^{9} \mu_{i} k_{i} & =k_{1}\left(\mu_{L}\left(e_{i}\right) \mu_{L}\left(e_{i}\right) \mu_{L}\left(e_{i}\right)\right)+k_{2}\left(\mu_{L}\left(e_{i}\right) \mu_{L}\left(e_{i}\right) \mu_{A}\left(e_{i}\right)\right) \\
& +k_{3}\left(\mu_{L}\left(e_{i}\right) \mu_{A}\left(e_{i}\right) \mu_{H}\left(e_{i}\right)\right)+k_{4}\left(\mu_{L}\left(e_{i}\right) \mu_{H}\left(e_{i}\right) \mu_{A}\left(e_{i}\right)\right)+k_{5}\left(\mu_{A}\left(e_{i}\right) \mu_{L}\left(e_{i}\right) \mu_{A}\left(e_{i}\right)\right) \\
& +k_{6}\left(\mu_{H}\left(e_{i}\right) \mu_{A}\left(e_{i}\right) \mu_{L}\left(e_{i}\right)\right)+k_{7}\left(\mu_{A}\left(e_{p}\right) \mu_{L}\left(e_{p}\right) \mu_{L}\left(e_{p}\right)\right)+k_{8}\left(\mu_{L}\left(e_{p}\right) \mu_{A}\left(e_{p}\right) \mu_{A}\left(e_{p}\right)\right) \\
& +k_{9}\left(\mu_{A}\left(e_{i}\right) \mu_{A}\left(e_{i}\right) \mu_{A}\left(e_{i}\right)\right)
\end{aligned}
$$

$$
\begin{aligned}
G\left(e_{d}\right)=\sum_{i=1}^{9} \mu_{i} k_{i} & =k_{1}\left(\mu_{L}\left(e_{d}\right) \mu_{L}\left(e_{d}\right) \mu_{L}\left(e_{d}\right)\right)+k_{2}\left(\mu_{L}\left(e_{d}\right) \mu_{L}\left(e_{d}\right) \mu_{A}\left(e_{d}\right)\right) \\
& +k_{3}\left(\mu_{L}\left(e_{d}\right) \mu_{A}\left(e_{d}\right) \mu_{H}\left(e_{d}\right)\right)+k_{4}\left(\mu_{L}\left(e_{d}\right) \mu_{H}\left(e_{d}\right) \mu_{A}\left(e_{d}\right)\right)+k_{5}\left(\mu_{A}\left(e_{d}\right) \mu_{L}\left(e_{d}\right) \mu_{A}\left(e_{d}\right)\right) \\
& +k_{6}\left(\mu_{H}\left(e_{d}\right) \mu_{A}\left(e_{d}\right) \mu_{L}\left(e_{d}\right)\right)+k_{7}\left(\mu_{A}\left(e_{d}\right) \mu_{L}\left(e_{d}\right) \mu_{L}\left(e_{d}\right)\right)+k_{8}\left(\mu_{L}\left(e_{d}\right) \mu_{A}\left(e_{d}\right) \mu_{A}\left(e_{d}\right)\right) \\
& +k_{9}\left(\mu_{A}\left(e_{d}\right) \mu_{A}\left(e_{d}\right) \mu_{A}\left(e_{d}\right)\right)
\end{aligned}
$$




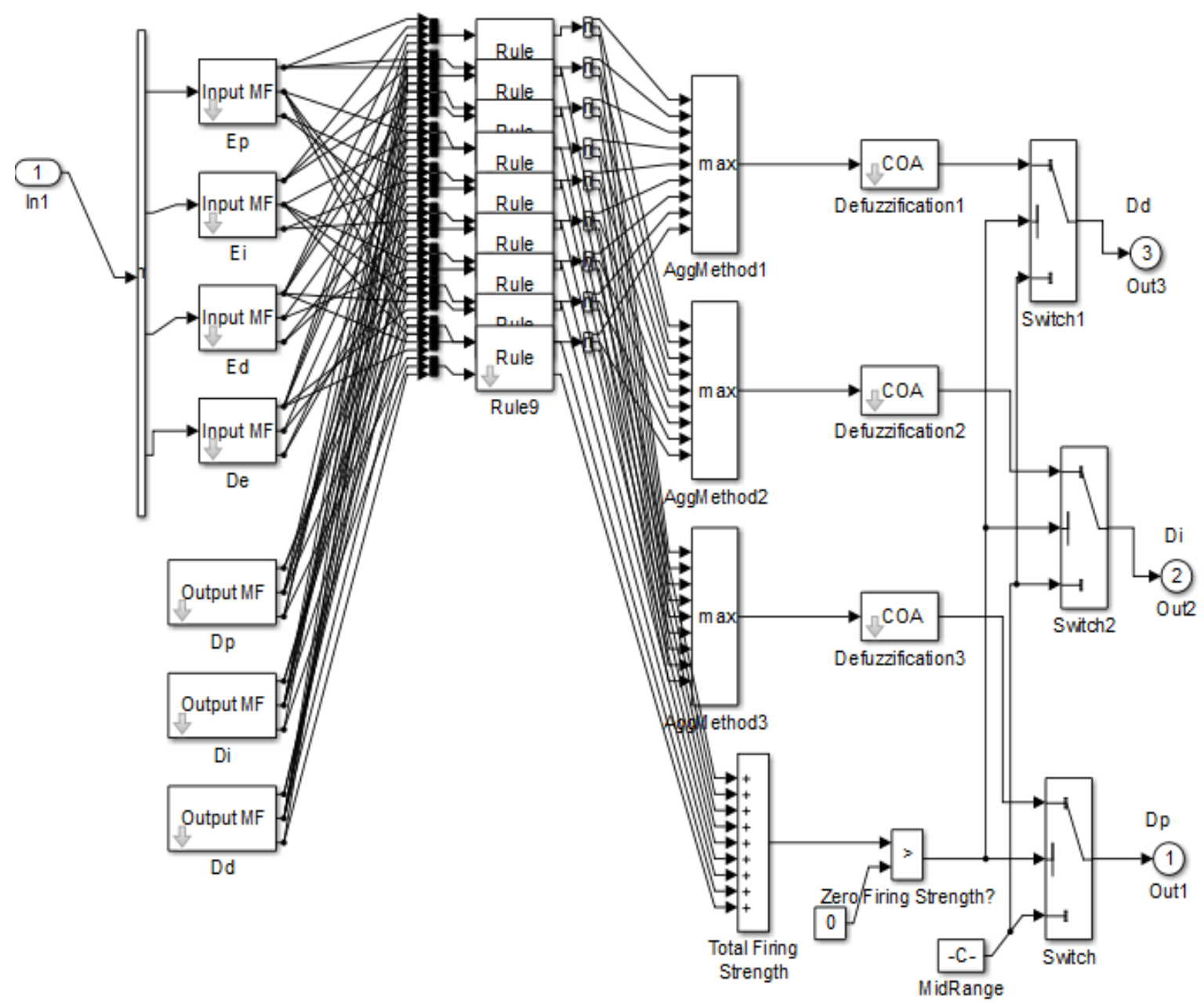

Figure 5. The network to be established

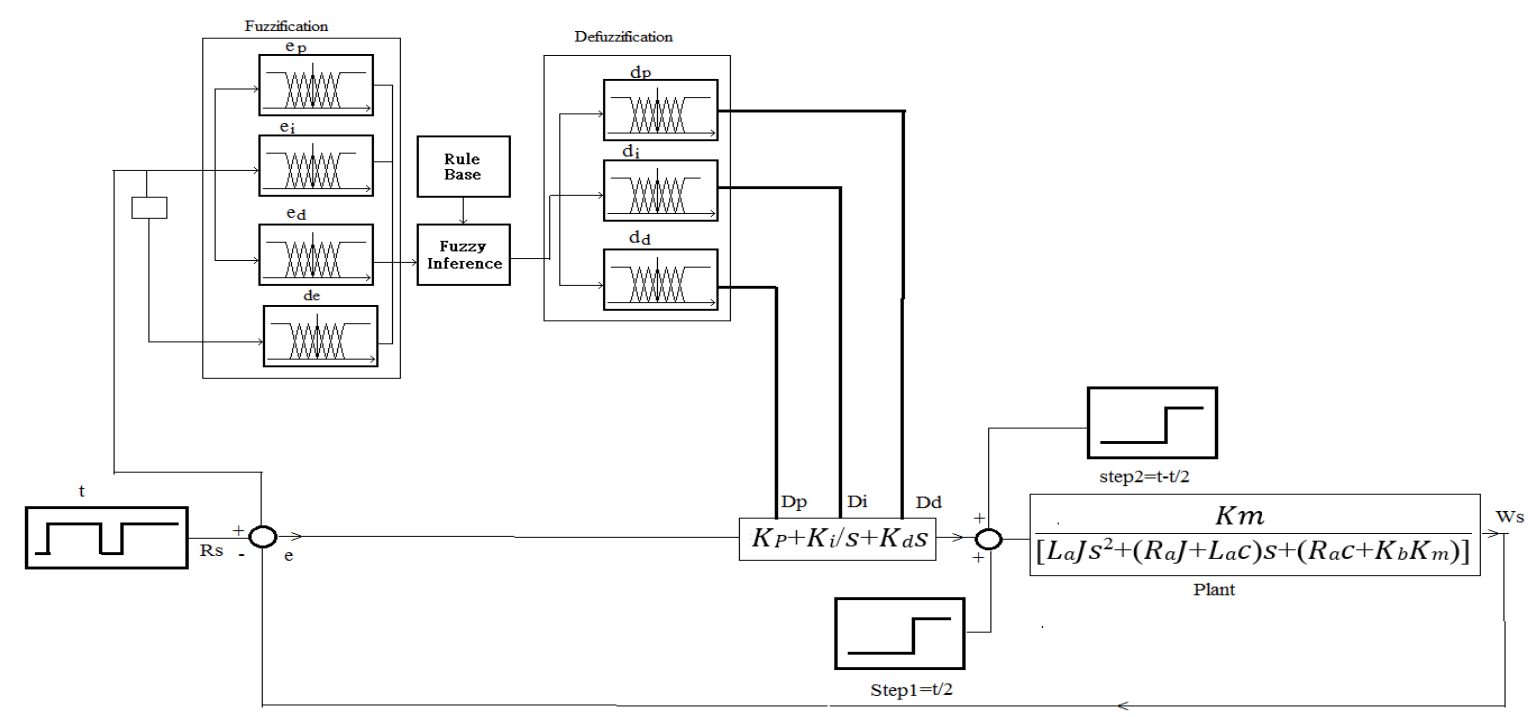

Figure 6. Fuzzy PID function block diagram

Figure 5 gives the network layout in Matlab Simulink, which gives error and error variation for $K_{P}, K_{I}$, and $K_{D}$ values. Fuzzy PID function block diagram is given in figure 6. 
Matlab Simulink model of the proposed system is given in figure 7. The DC motor is driven with a load in the form of pulse width modulation. 3-IGBT switches are used to control the motor. The IGBT1 and IGBT2 switches divide the total operating time into two equal parts. The IGBT and IGBT1 switches apply the 200 volt source to the motor for the first time period, while the IGBT and IGBT2 switches apply the 300 volt source to the motor for the first time period. Therefore, starting at a low speed is ensured, and then the engine accelerates. PID controls control these two time periods. Figure 8 shows the PWMs controlling the switches and the steps that divide these PWM into two equal parts. The dc motor used in the system has $240 \mathrm{~V}$ voltage, $16.2 \mathrm{~A}$ armature current, $5 \mathrm{hp}$ power. $\mathrm{Kp}=0.6, \mathrm{~K}=0.11, \mathrm{Kd}=0.0018$ values are used for the controls.

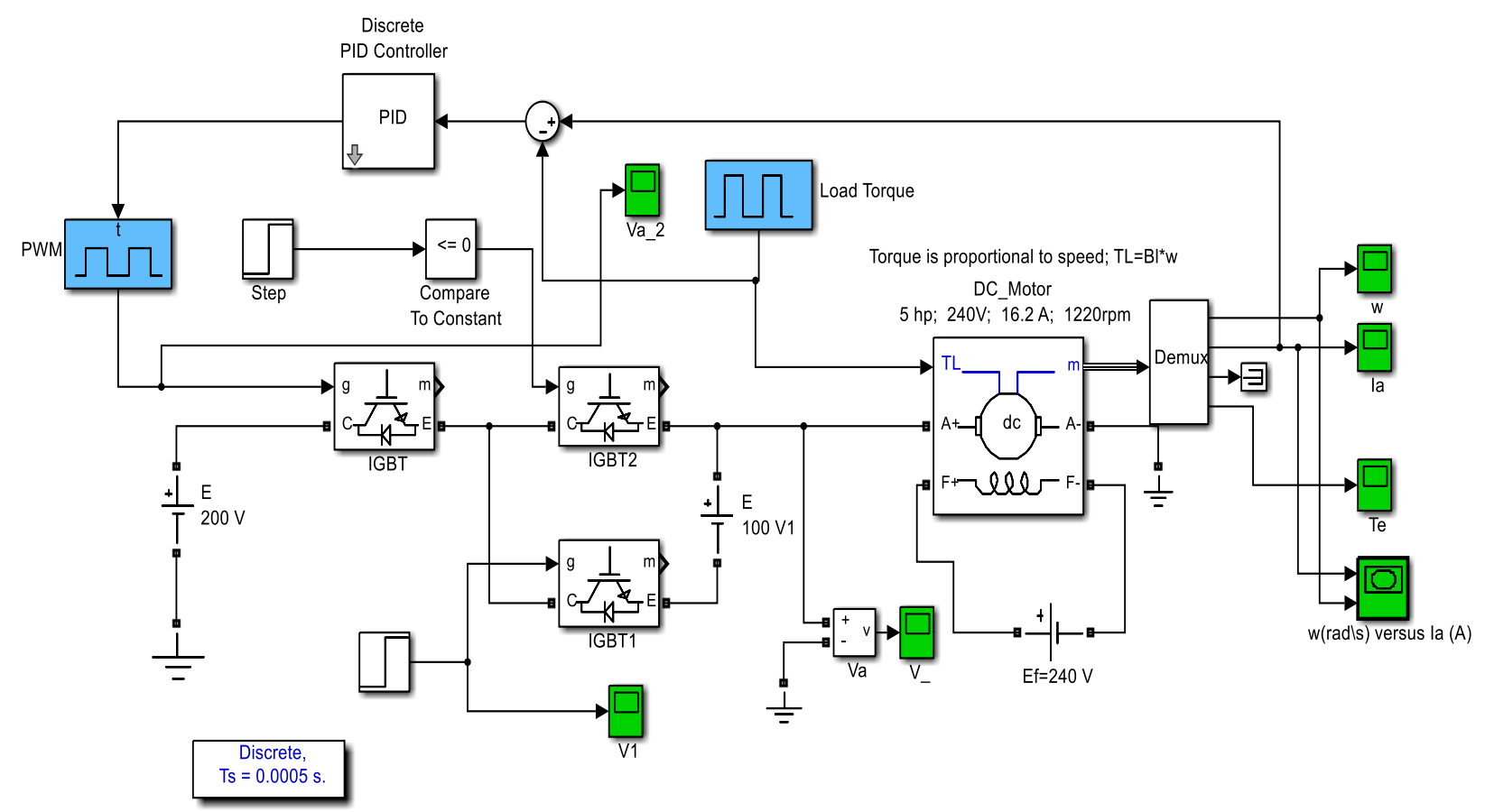

Figure.7 Matlab Simulink model of the proposed system
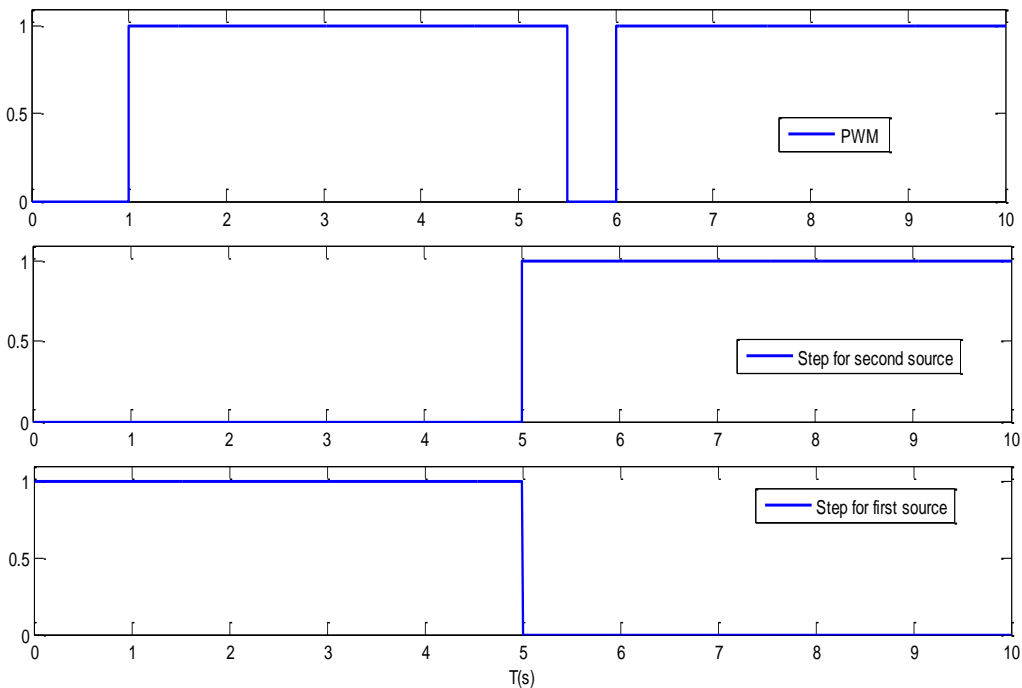

Figure 8 the PWMs controlling the switches and the steps dividing these PWM into two equal parts. 


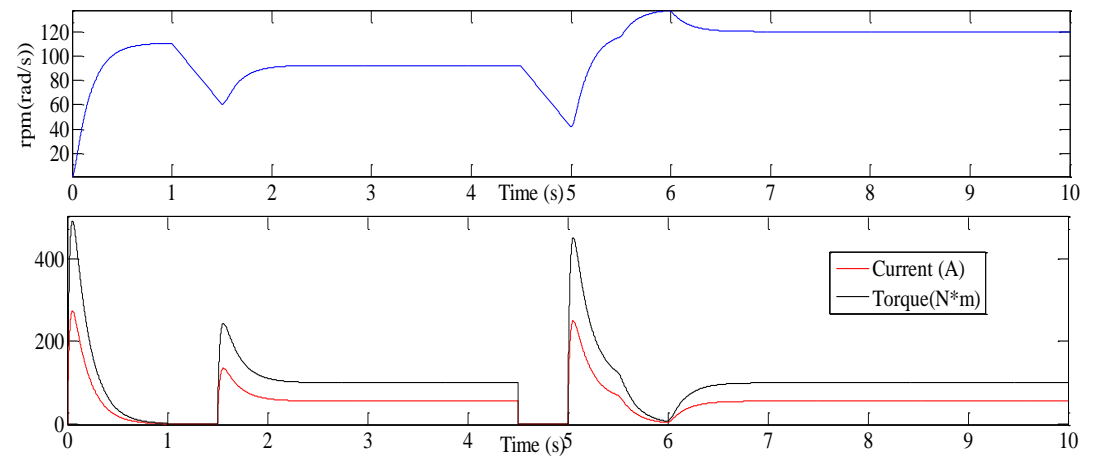

Figure 9. The proposed system is operated using $\mathrm{P}$ control for two different steps

When the proposed system is operated using P control for two different steps, the motor speed, motor current, and torque are as given in Figure 9. While high oscillations occur during the 0 second and $5^{\text {th }}$ second periods, which are the starting points of time when $\mathrm{p}$ control is used. Settlement time is 2.2 seconds for the first time period and 6.6 seconds for the second step. While the motor speed drops by $60 \mathrm{rad} / \mathrm{s}$ in the first time and the second time period, the $\mathrm{P}$ control cannot provide current and torque to the motor in these time period. When the proposed system is operated using PI and PID controls for two different steps, the motor speed, motor current, and torque are as given in Figure 10.
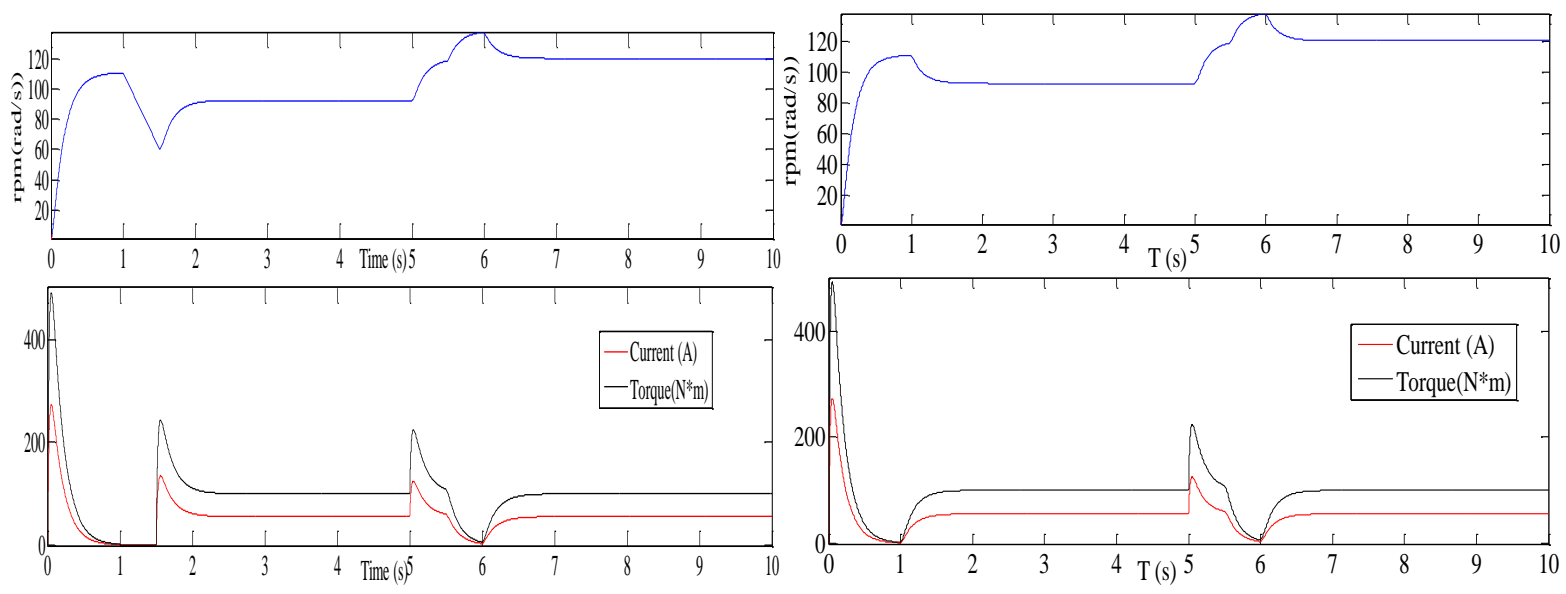

Figure 10. a) the proposed system is operated using PI control for two different steps) the proposed system is operated using PID control for two different steps

Although the oscillations occur during the 0 second and $5^{\text {th }}$ second periods, which are the starting points of time when PI control is used, the oscillations are lower than P control causing oscillations. Settlement time is 2.2 $\mathrm{s}$ for the first time period and $6.5 \mathrm{~s}$ for the second step. While the motor speed drops by $60 \mathrm{rad} / \mathrm{s}$ in the transition from the first time period, the PI control can provide current and torque to the motor in second time period. When the proposed system is operated using PID control for two different steps, the motor speed, Motor current, and torque are as given in Figure 10b. Although the oscillations occur during the 0 second and $5^{\text {th }}$ second periods, which are the starting points of time when PID control is used, the oscillations are lower than P control causing oscillations. Settlement time is 1.5 seconds for the first time period and 6.5 seconds for the second step. The PID control can provide current and torque to the motor in total time period. If different controllers are used in two different steps of the total time span, the circuit can be set up in Matlab Simulink as in figure 11. 


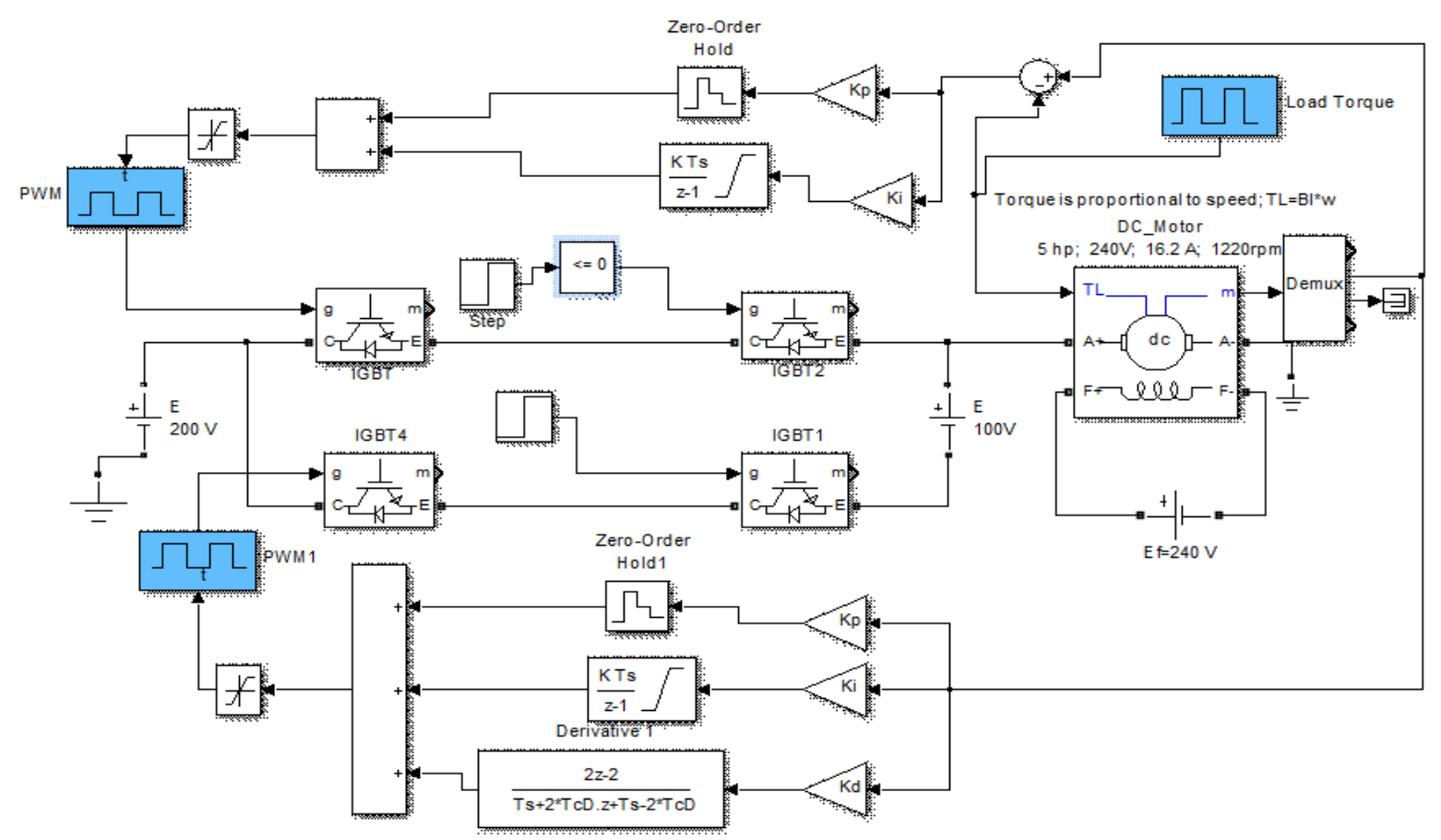

Figure 11. The proposed system is operated using PID and PI controls for two different steps
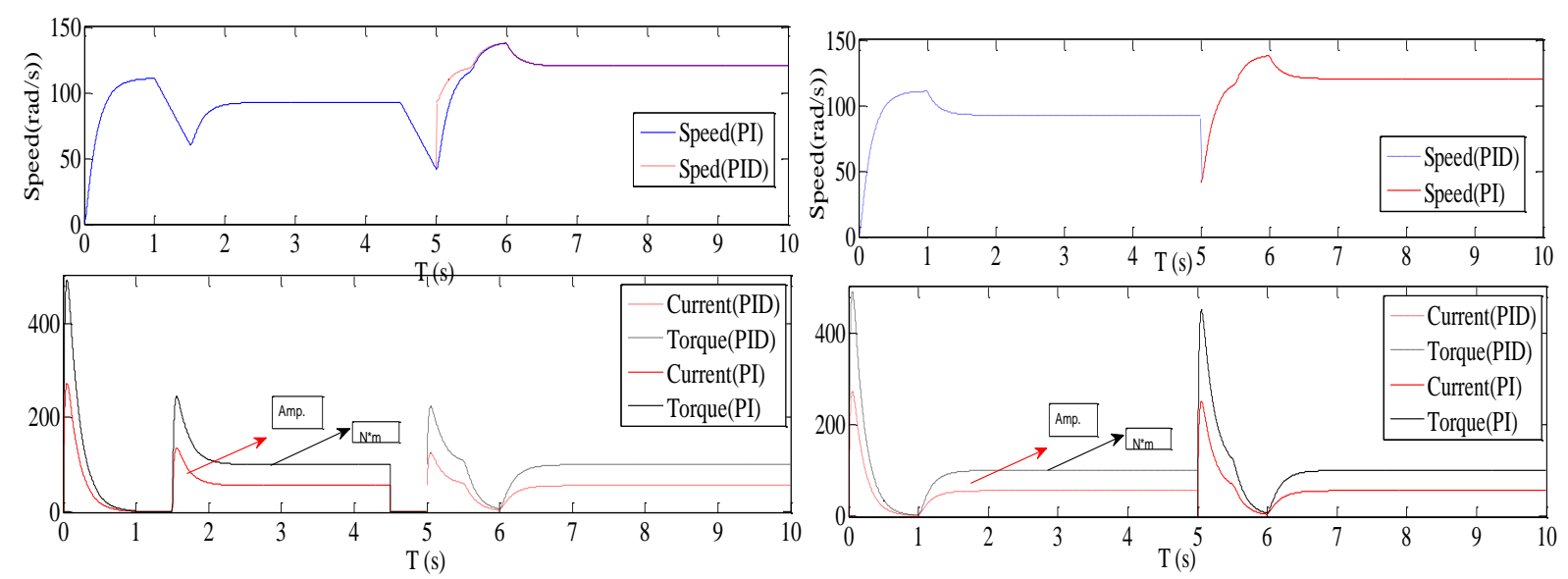

Figure 12. a) First time period for PI and second time period PID, b) first time period for PID and second time period PI
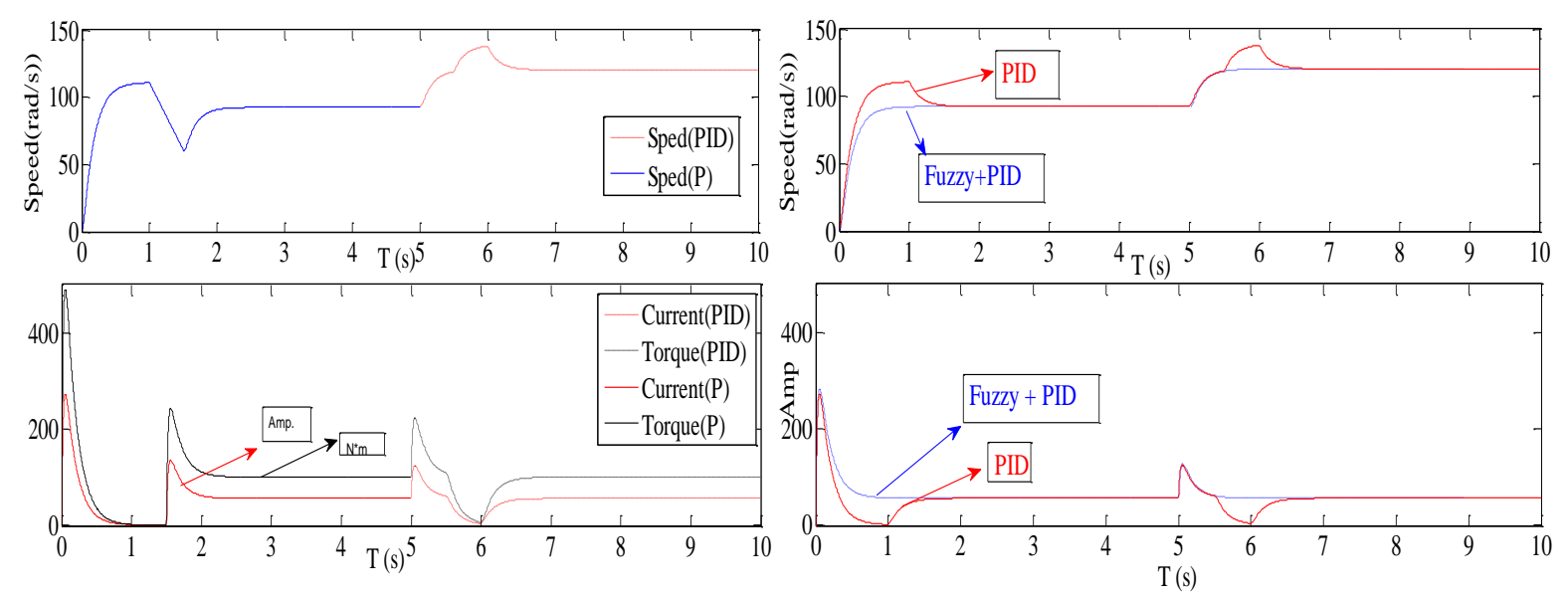

Figure 13. a) First time period for $\mathrm{P}$ and second time period PID, b) FUZZY+PID and PID control 
If PI is used in the first time zone step and PID is used in the second time step, the motor speed current and torque will be as in figure 12. While the sweating time is 2.2 seconds in the first time frame, when starting with PID, this settling time decreases to 1.5 seconds. These results show that in such a system, the system can be controlled with PI after starting control with PID. If starting with P control and continuing to control the system with PID control, motor torque, motor current, and motor speed are obtained as shown in Figure 13a. When the DC motor FUZZY + PID is controlled as shown in the control diagram in Figure 6, the motor torque, the motor current becomes as shown in Figure 13b.

In the first time period, the $\mathrm{P}$ control flows to the motor between 1 and 1.4 seconds and cannot provide voltage, while the motor speed drops to $60 \mathrm{rad} / \mathrm{s}$ during this period. In the second time period, PID control provides continuous current and torque to the motor, allowing the speed to settle at $12.2 \mathrm{rad} / \mathrm{s}$ without decreasing in figure 13a. Figure 13b compares the currents and speeds of the DC motor under PID and FUZZY + PID control. While the PID control stabilizes the motor speed in 1.5 seconds, the FUZZY + PID control stabilizes the motor speed in 1 second. While the PID control stabilizes the motor current in 1.5 seconds, the FUZZY + PID control stabilizes the motor current in $1 \mathrm{sec}$. In time transition periods, FUZZY + PID provides faster settlement compared to PID, while it is lost in oscillations.

Starting the system again by changing the working order of the steps, then the motor will be driven with a voltage of $300 \mathrm{~V}$ in the first half of the total driving time. Then, if it is the second step of the total driving time, the speed of the motor will be reduced by driving with a lower voltage of 200 volts. When the motor is driven with PID and PI controller at $300 \mathrm{~V}$ starting voltage, the motor values are given in Figure 14. After that, as the motor is driven with PID and P controllers at $300 \mathrm{~V}$ starting voltage, the motor values are given in Figure 14. In Figure 14b, when the motor is driven with PID, the speed settlement time is 1.2 seconds, while the speed of the motor controlled by PI becomes stable in 2.1 seconds. In figure 14a, the PI control forces the motor to stop after 7.6 seconds by reducing its speed.
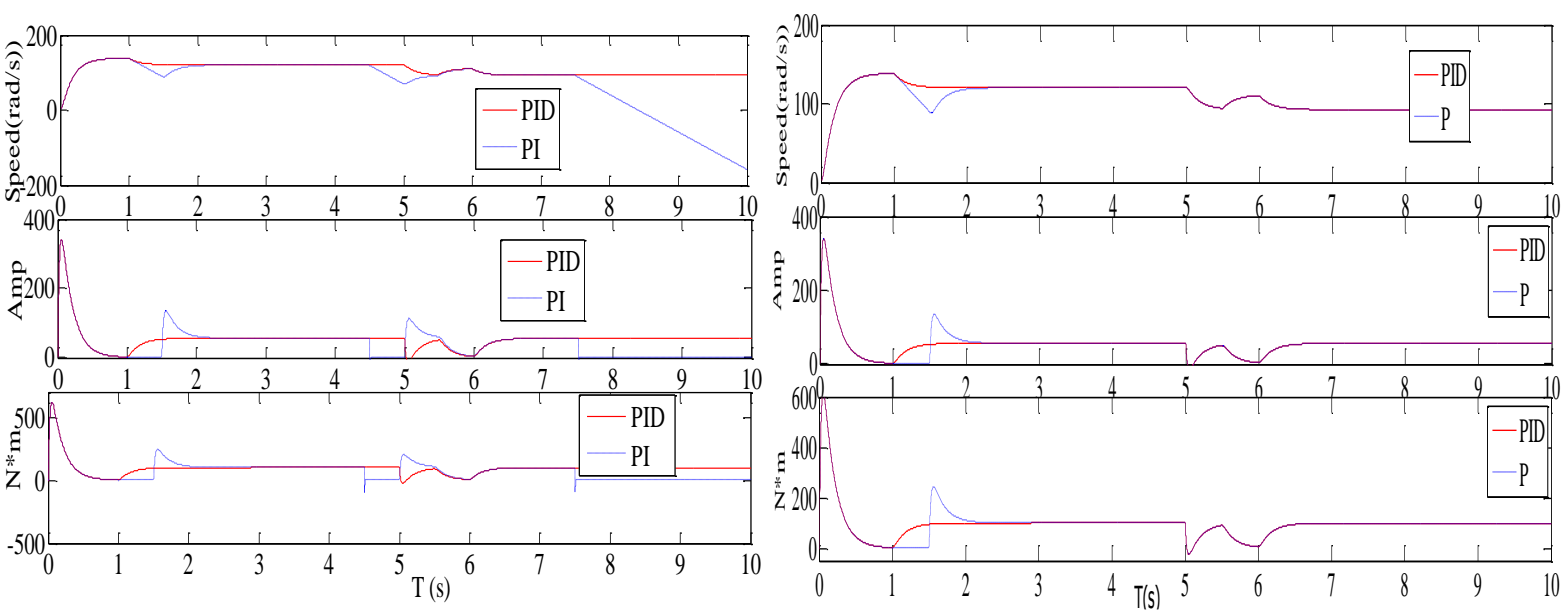

Figure 14. a) the motor driven with PID and PI controller at 300V,b) the motor driven with PID and P controller at $300 \mathrm{~V}$
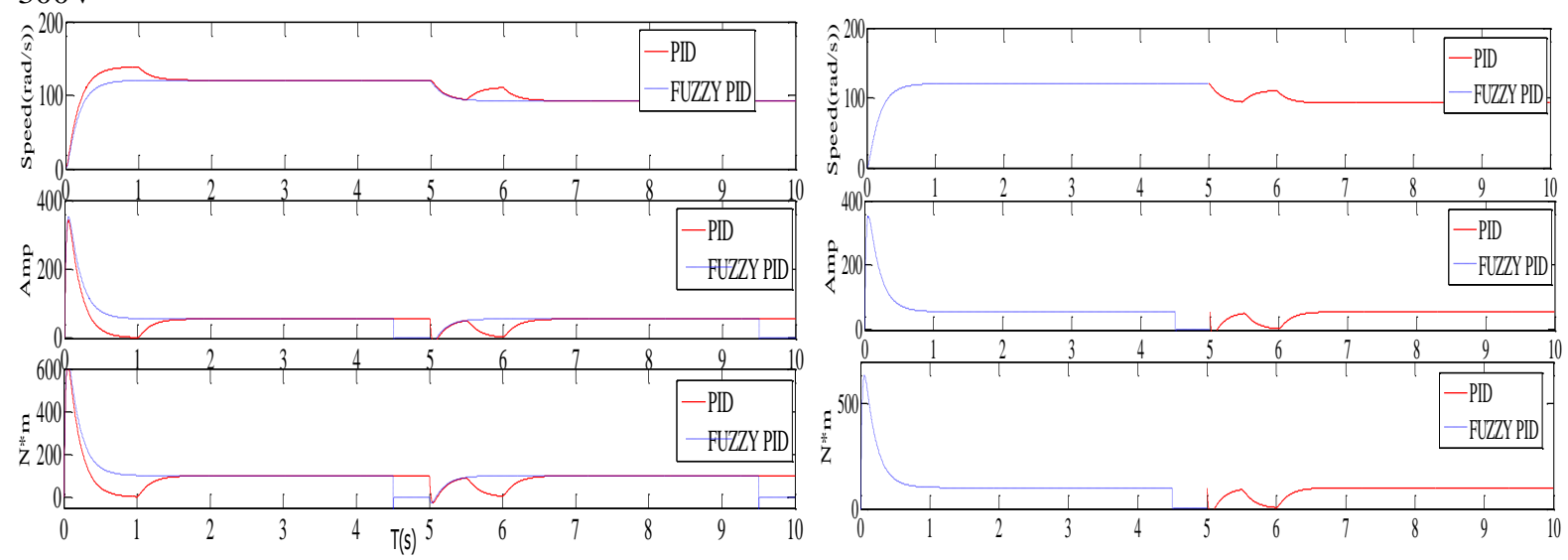

Figure15. a) The motor driven with PID and FUZZY+PID controller at 300V,b) the motor driven with PID and FUZZY at $300 \mathrm{~V}$ 

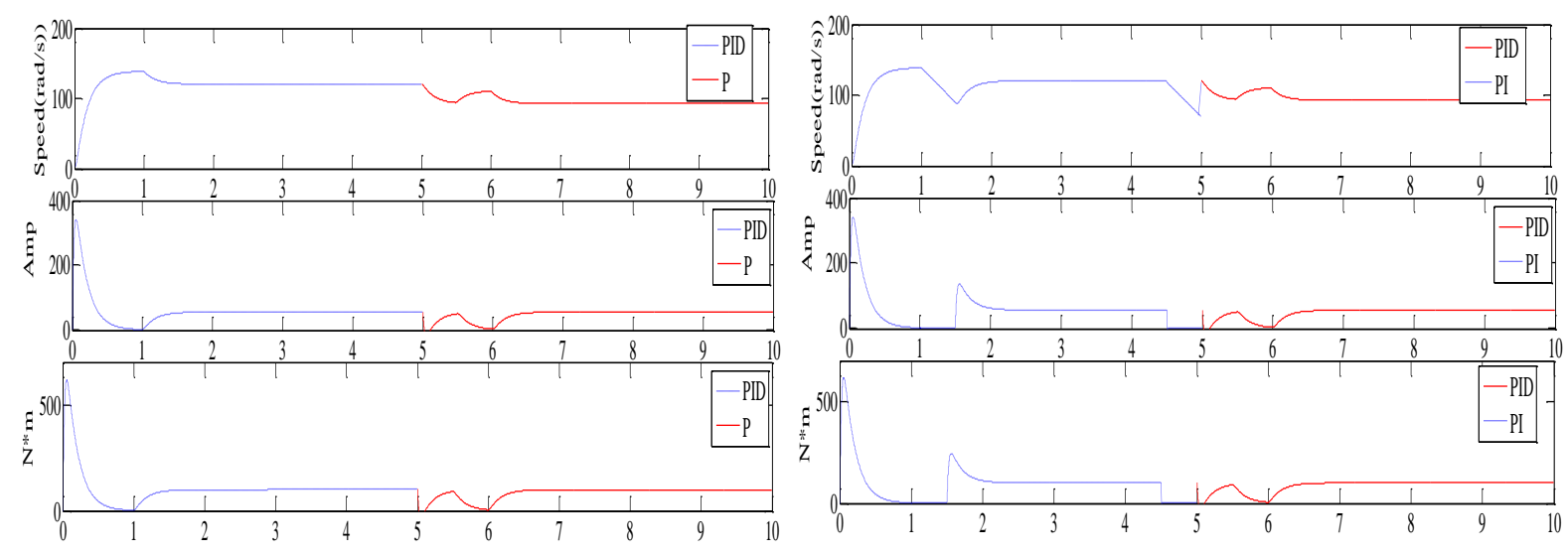

Figure16. a) The motor driven with PID and P at 300V,b) the motor driven with PID and PI at 300V

If the motor is driven with PID and FUZZY PID controller at $300 \mathrm{~V}$ starting voltage, the motor values are given in Figure 15. As the motor is driven with PID, the speed settlement time is 1.6 seconds, the speed of the motor controlled by FUZZY+PID becomes stable in 0.9 seconds in Figure 15a. In Figure 15b, the motor is driven using FUZZY PID controls for 0 to 5 seconds by performing flexible closed-loop control. During this time, the motor becomes stable at $122 \mathrm{rad} / \mathrm{s}$ in 0.9 seconds. After 0.5 seconds, the system is driven with $\mathrm{P}$ control. Thus, the advantage of the FUZZY PID in the first take-off is utilized. In figure 16a, PID and P option closed-loop control is performed, while in figure 16b, PID and PI mixed closed-loop control is performed. In Figure 16, when the engine is started with $\mathrm{P}$ control in the first step, the settling time of the engine speed is 1.6s, while in Figure 16b, the settling time of the engine speed with PI control is 2.1 seconds. In figures 14, 15, and 16, when the engine is driven with 300 volts in the first step driving time, the engine speed is $1220 \mathrm{rpm}$. During the second step driving time, the motor speed drops below $1220 \mathrm{rpm}$ because motor operating low voltage in second step.

Looking at the results obtained, flexible closed-loop control is successfully achieved by using different controls within the same control system in different time periods. While the system control starts with $\mathrm{P}$, it automatically switches to PID control during the application of the request, and the operation can continue with a different control. It is seen that success can be achieved by applying FUZZY + PID control to obtain better results in the piecewise flexible control method of this DC motor.

\section{CONCLUSION:}

In this article, flexible closed-loop P, PI, PID, FUZZY + PID control of DC motor has been made. Pulse torque and Pulse current applied to the motor were divided into time intervals in closed-loop control and different controls were activated at different time intervals. While the motor in the starting voltage of $300 \mathrm{~V}$ driven with PID, the speed settlement time was 1.6 seconds, the speed of the motor controlled by FUZZY+PID became stable in 0.9 seconds. The motor was driven using FUZZY PID controls for 0 to 5 seconds by performing flexible closed-loop control. During this time, the motor became stable at $122 \mathrm{rad} / \mathrm{s}$ in $0.9 \mathrm{~s}$. After 0.5 seconds, the system was driven with P control. Thus, the advantage of the FUZZY PID in the first take-off was utilized. While PID and P option closed-loop control were performed, PID and PI mixed closed-loop control was performed. For the engine started with $\mathrm{P}$ control in the first step, the settling time of the engine speed was $1.6 \mathrm{~s}$, for the engine was started with PI control in the first step, the settling time of the engine speed was $2.1 \mathrm{~s}$. FUZZY + PID controllers control the current and torque in the form of pulse width modulation better than the other P and PI, PID controls, providing current and torque to the motor in a short time and with less oscillation. P and PI were insufficient for this situation during the entire running time of the motor. Therefore, FUZZY + PID stabilized motor parameters in a shorter time than other control methods according to conventional P, PI, and PID, while eliminating oscillation in transition times.

\section{REFERENCES:}

Arulmozhiyal, R., \& Kandiban, R. 2012. Design of fuzzy PID controller for brushless DC motor. In 2012 International Conference on Computer Communication and Informatics (pp. 1-7). IEEE. 
Assefa, T. T., Adametie, T. F., Yimam, A. Y., Belay, S. A., Degu, Y. M., Hailemeskel, S. T., ... \& Prasad, P. V. 2021. Evaluating Irrigation and Farming Systems with Solar MajiPump in Ethiopia. Agronomy, 11(1), 17.

Can, E., \& Sayan, H. H. 2017. The performance of the DC motor by the PID controlling PWM DC-DC boost converter. Tehnički glasnik, 11(4), 182-187

Do Khac Tiep, K. L., Im, D. Y., Kwak, B., \& Ryoo, Y. J. 2018. Design of fuzzy-PID controller for path tracking of mobile robot with differential drive. International Journal of Fuzzy Logic and Intelligent Systems, 18(3), 220-228.

Jaya, A., Purwanto, E., Fauziah, M. B., Murdianto, F. D., Prabowo, G., \& Rusli, M. R. 2017. September). Design of PID-fuzzy for speed control of brushless DC motor in dynamic electric vehicle to improve steady-state performance. In 2017 International Electronics Symposium on Engineering Technology and Applications (IES-ETA) (pp. 179-184). IEEE.

Kristiyono, R., \& Wiyono, W. 2021. Autotuning Fuzzy PID Controller for Speed Control of BLDC Motor. Journal of Robotics and Control (JRC), 2(5), 400-407

Latif, A., Arfianto, A. Z., Widodo, H. A., Rahim, R., \& Helmy, E. T. 2020. Motor DC PID system regulator for mini conveyor drive based-on MATLAB. Journal of Robotics and Control (JRC), 1(6), 185-190.

Mahmud, M., Motakabber, S. M. A., Alam, A. H. M. Z., \& Nordin, A. N. (2020). Control BLDC Motor Speed using PID Controller. International Journal of Advanced Computer Science and Applications (IJACSA), 11(3), 477-481.

Mondal, A., Sarkar, P., \& Hazra, A. (2020). A unified approach for PI controller design in delta domain for indirect field-oriented control of induction motor drive. Journal of Engineering Research, 8(3).

Mseddi, A., Aloui, H., Vido, L., \& Coty, A. 2021. Experimentally validated model of a self-switched solar motor for pumping application. Journal of Renewable and Sustainable Energy, 13(1), 013501.

Premkumar, K., \& Thamizhselvan, T. 2021. Analysis and investigation of PID, Fuzzy PD, Fuzzy PI Speed Controlled DC motor. International Transaction on Power and Energy Systems, 1(1), 48-58.

Saeteros, M., Paucar, W., Molina, C., \& Caiza, G. 2019. Development and Analysis of a PID Controller and a Fuzzy PID. In International Conference on Computer Science, Electronics and Industrial Engineering (CSEI) (pp. 143-154). Springer, Cham.

Tang, W. J., \& Cao, S. Y. 2018. A fast realization method of fuzzy pid control for dc motor. In 2018 37th Chinese Control Conference (CCC) (pp. 5131-5135). IEEE.

Workineh, T. G., Taye, B. Z., Nebey, A. H., \& Getie, E. M. 2021. PI-like fuzzy based synchronous SEPIC converter control for PV-fed small scale irrigation DC pump. Cogent Engineering, 8(1), 1893590

Yunardi, R. T., Arifianto, D., Bachtiar, F., \& Prananingrum, J. I. 2021. Holonomic Implementation of Three Wheels Omnidirectional Mobile Robot using DC Motors. Journal of Robotics and Control (JRC), 2(2), 6571.

Rezaie, H., Khoshsaadat, A., Moghani, J. S., \& Rastegar, H. (2020). A new fluctuating power decoupling method based on ANFIS and PR control structures applicable to single-phase PWM rectifiers. JOURNAL OF ENGINEERING RESEARCH, 8(1), 211-230. 